\title{
Three-year follow-up of serum 25-hydroxyvitamin $D$, parathyroid hormone, and bone mineral density in nursing home residents who had received 12 months of daily bread fortification with $125 \mu \mathrm{g}$ of vitamin $D_{3}$
}

Veronica Mocanu ${ }^{1 *}$ and Reinhold Vieth ${ }^{2,3}$

\begin{abstract}
Background: We conducted a single-arm clinical trial in institutionalized seniors, on the effects of high-dose vitamin D3-fortified bread daily intake (clinicaltrials.gov registration NCT00789503).

Methods: At 1 and 3 years after the dietary fortification was stopped, serum 25-hydroxyvitamin D (25(OH)D), parathyroid hormone (PTH) and bone mineral density were measured in 23 of the original study subjects, aged 60-82 years who had consumed bread buns (100 g) fortified with $320 \mathrm{mg}$ elemental calcium and $125 \mu \mathrm{g}(5,000 \mathrm{IU})$ vitamin D3 daily for one year.

Results: At the end of the 1-year supplementation phase (receiving vitamin D3 fortified bread daily), mean (SD) serum 25(OH)D was $127.3 \pm 37.8 \mathrm{nmol} / \mathrm{L}$ (baseline for this follow-up). At 1-year follow-up, the serum 25(OH)D was $64.9 \pm 24.8 \mathrm{nmol} / \mathrm{L}$ ( $p=0.001$, vs. baseline); and at 3-year follow-up it was $28.0 \pm 15.0 \mathrm{nmol} / \mathrm{L}$ ( $p=0.001 \mathrm{vs}$. baseline). Serum PTH was $18.8 \pm 15.6 \mathrm{pg} / \mathrm{ml}$ at baseline while at Year 3 it was $48.4 \pm 18.4 \mathrm{pg} / \mathrm{ml}$ ( $p=0.001 \mathrm{vs}$. baseline). Lumbar spine BMD did not change from baseline to Year 3. However, by Year 3, hip BMD had decreased $\left(0.927 \pm 0.130 \mathrm{~g} / \mathrm{cm}^{2}\right.$ vs. $0.907 \pm 0.121 \mathrm{~g} / \mathrm{cm}^{2}, p=0.024$ ).

Conclusion: Vitamin D nutritional status exhibits a long half-life in the body, and a true steady-state plateau may not even be reached 1 year after a discontinuation in dose. Furthermore, once the need for vitamin $\mathrm{D}$ has been established, based on a low baseline serum $25(\mathrm{OH}) \mathrm{D}$ concentrations, the appropriate action is to maintain corrective vitamin D supplementation over the long term.
\end{abstract}

Trial registration: Clinical trial registration number: NCT00789503

Keywords: Geriatrics, Cholecalciferol, Osteoporosis, Vitamin D deficiency, Bread fortification

\section{Background}

Older adults are particularly susceptible to vitamin D insufficiency [1] particularly in nursing homes [2]. In Romania, serum 25-hydroxyvitamin D $(25(\mathrm{OH}) \mathrm{D})$ concentrations in institutionalized seniors were $28.5 \pm 10.8 \mathrm{nmol} / \mathrm{L}$ [3], far below the minimum $50 \mathrm{nmol} / \mathrm{L}$ that the US Institutes of

\footnotetext{
* Correspondence: vmocanu@iasi.mednet.ro

'Department of Pathophysiology, Grigore T. Popa University of Medicine and Pharmacy, 16 Universitatii str, lasi 700115, Romania

Full list of author information is available at the end of the article
}

Medicine has set as the basis for its latest recommended dietary allowance (RDA) [4].

The serum 25(OH)D concentrations likely required to minimize the risk of falls and fractures has been estimated to be between 75 and $100 \mathrm{nmol} / \mathrm{l}$ [5]. We previously provided evidence to support this recommendation by completing a single-arm clinical trial in which we provided institutionalized seniors with bread fortified each day with $125 \mu \mathrm{g}(5,000 \mathrm{IU})$ of vitamin $\mathrm{D}_{3}$ [3]. This dietary protocol ensured that virtually all of the adults achieved serum 25 $(\mathrm{OH}) \mathrm{D}$ concentrations of at least $75 \mathrm{nmol} / \mathrm{L}$. Here we 
report the long-term follow-up of study subjects at 1 and 3 years after discontinuing the clinical trial. During this time, the subjects have returned to their previous standard of health care, which did not provide a vitamin D supplement.

\section{Subjects and methods}

\section{Study population and design}

The single-arm clinical trial (clinicaltrials.gov registration NCT00789503) initially enrolled 45 patients (28 women and 17 men), 58 to 89 years of age (71 \pm 6.9 years), all residing in a nursing home located in Iasi, Romania (Latitude $47^{\circ} \mathrm{N}$ ) [3]. At the end of the one-year supplementation protocol (consumption of bread buns fortified with 5,000 IU vitamin $\mathrm{D}_{3}$ per daily serving) [3], 33 patients were assessed by Dual-energy X-ray absorptiometry (DXA) (January 2005). Initial and final bone mineral density (BMD) data were available for 33 subjects. These patients were retested by DXA one and three years after the vitamin D protocol was discontinued (January 2006 and January 2008, respectively).

\section{Study protocol}

In the original study, all subjects received $125 \mu \mathrm{g}$ (5,000 IU) vitamin $\mathrm{D}_{3} /$ day and $800 \mathrm{mg}$ calcium carbonate/day (320 mg of elemental calcium) for $1 \mathrm{yr}$.

Bone mineral density (BMD) of the lumbar spine and proximal femur was measured at baseline and after 12 months of vitamin $\mathrm{D}_{3}$ supplementation [3]. The BMD measurements at the end of vitamin $D_{3}$ supplementation were taken as the baseline values for this follow-up report (i.e. "baseline" refers to measures obtained at the end of $1 \mathrm{yr}$ of vitamin D), and additional measurements were obtained after 12 and 36 months of follow-up study. Blood for serum calcium, 25(OH)D and serum PTH was obtained at baseline and at 1 and 3 years follow-up.

At the beginning of the original study, the 10-day food records obtained from the nursing home showed that the per-day vitamin $\mathrm{D}$ intake was $84 \mathrm{IU}$, while calcium intake was $717 \mathrm{mg}$. The participants did not take supplements of calcium, vitamin $\mathrm{D}$, or both in the preceding 36 mo.

Both the intervention and follow-up studies were approved by the Human Investigation Review Committee at Grigore T. Popa University, and written informed consent was obtained from each subject.

\section{Blood collection and analytical methods}

Fasting blood samples were collected at baseline and after 1 and 3 years of follow-up study. Serum and plasma were kept frozen until analysis.

Serum calcium concentrations were measured by standard laboratory methods. Serum 25(OH)D concentrations were assayed by HPLC method [6] (results were validated through the DEQAS proficiency survey (www.deqas.org) for $25(\mathrm{OH}) \mathrm{D}$, and the results were within the all-laboratory methods mean). Serum intact PTH was measured by an enzyme-amplified "two-step" sandwich-type immunoassay (DSL, Webster, Texas, USA) with an inter-assay $\mathrm{CV}$ ranging from 6.0 to $6.3 \%$ (normal range for adults 40-70 years of age, pg/ml). The BMD of the lumbar spine, femoral neck and trochanter were measured by dual energy x-ray absorbtiometry (Hologic, Delfi A and Delfi W). The calibration of bone densitometer was performed by scanning the European Spine Phantom. All measurements were performed by the same experienced technician.

\section{Statistical analysis}

Statistical analyses were performed using SPSS version 15.0 (SPSS Inc, Chicago). Data are expressed as mean \pm SD. The distributions of all variables were tested with Kolmogorov-Smirnov tests. Descriptive statistics (mean and SD) were determined for all variables. Effects of the follow-up after the vitamin D protocol was completed were examined using the paired t-test versus the "baseline" values for each subject, which in the context of the present follow-up report are those values obtained at the end of the 1-yr intervention with vitamin Dfortified bread. A two-way repeated-measures ANOVA was conducted to explore the impact of sex and age on outcome variables (lumbar and hip BMD, concentrations of serum calcium, 25(OH)D, and PTH).

\section{Results}

\section{Characteristics of the population}

Thirty-three older nursing home residents were included into the follow-up study, which represents the population of participants having completed the Vitamin D fortified bread intervention. Baseline characteristics of the patients are shown in Table 1. Two patients withdrew from the study before the 12 month-follow-up visit. One

\begin{tabular}{|c|c|c|c|}
\hline Characteristic & Males & Females & Total \\
\hline Number & $11(33 \%)$ & $22(66.6 \%)$ & $33(100 \%)$ \\
\hline Age (yr) & $67.0 \pm 5.2$ & $69.1 \pm 5.1$ & $68.3 \pm 5.6$ \\
\hline Weight (kg) & $81.5 \pm 11.9$ & $71.2 \pm 10.2$ & $76.3 \pm 11.3$ \\
\hline Height (cm) & $167.0 \pm 4.3$ & $154.0 \pm 5.5$ & $159.4 \pm 7.3$ \\
\hline BMI $\left(\mathrm{kg} / \mathrm{cm}^{2}\right)$ & $29.3 \pm 4.6$ & $30.5 \pm 4.2$ & $30.0 \pm 4.3$ \\
\hline Vitamin D intake $(\mu \mathrm{g} / \mathrm{d})$ & $2.1 \pm 1.1$ & $1.5 \pm 0.9$ & $1.7 \pm 1.0$ \\
\hline Calcium intake (mg/d) & $938 \pm 432$ & $758 \pm 341$ & $780 \pm 387$ \\
\hline
\end{tabular}

Data expressed in mean \pm SD. 
patient died, and other 7 withdrew by 3-year follow-up. Complete, 36-month follow-up data were available for 23 subjects. Twenty-three patients had initial and final of BMD data by 36 month follow-up study.

\section{Measurements of serum 25-hydroxyvitamin D}

At baseline for the original clinical trial, mean serum $25(\mathrm{OH}) \mathrm{D}$ was $28.5 \pm 10.8 \mathrm{nmol} / \mathrm{L}$ and, after 12 months of $5,000 \mathrm{IU} / \mathrm{d}$ vitamin $\mathrm{D}_{3}$ bread supplementation, this increased to $125.6 \pm 38.8 \mathrm{nmol} / \mathrm{L}$ [3]. Twelve months after the end of the clinical trial, mean serum $25(\mathrm{OH}) \mathrm{D}$ was $64.9 \pm 24.8 \mathrm{nmol} / \mathrm{L}$, a significant decline from its peak value $(\mathrm{p}=0.0001)$ (Table 2$)$; however, serum 25 $(\mathrm{OH}) \mathrm{D}$ concentrations exceeded $50 \mathrm{nmol} / \mathrm{L}$ in $65 \%$ of the patients (15 of 23 patients). However, at 36 month follow-up mean serum $25(\mathrm{OH}) \mathrm{D}$ has essentially returned to the baseline value of the original clinical trial $(28.0 \pm$ $15.0 \mathrm{nmol} / \mathrm{L})$.

\section{Measurements of serum calcium and PTH}

There were no significant differences in serum calcium concentrations at baseline versus 12 and 36 month followup (Table 2). Compared to the end-of clinical trial, PTH concentrations significantly increased by 12 months of follow-up ( $\mathrm{p}=0.0001)$ and by 36 months $(\mathrm{p}=0.0001)$ but remained within the reference range. No treatment-related adverse events were observed during follow-up.

\section{Bone mineral density measurements}

Upon withdrawal of vitamin $\mathrm{D}_{3}(125 \mu \mathrm{g})$ supplementation, there were no significant differences in the mean percentages of change in lumbar spine; the mean percentages of change from baseline in lumbar spine BMD at 1 -year follow-up was $-0.31 \%$ and at 3 -year follow-up was $1.03 \%$. Statistically significant changes from baseline were noticed in hip BMD (Table 2); the mean relative change from baseline in hip BMD at 1-year follow-up was $-1.52 \%$ and at 3 -year follow-up was $-1.99 \%$.

\section{Discussion}

Corrective action was not implemented after the original clinical trial was completed because the study subjects returned to their standard of care. Until the end of this follow-up, there was no compelling reason to provide more vitamin D. Although it was reassuring that at follow-up Year 1, the serum 25(OH)D was appropriate for the group, the data at follow-up Year 3 show that 25 $(\mathrm{OH}) \mathrm{D}$ had not established its new plateau. Previous studies suggests that when vitamin $\mathrm{D}$ supplementation is stopped, the serum $25(\mathrm{OH}) \mathrm{D}$ concentrations exhibit an apparent half-life of two months [7]. However, the decline in serum $25(\mathrm{OH}) \mathrm{D}$ observed here exceeded 1 year (i.e. the decline exceeded six of the presumptive 2-month half-life); therefore, the apparent half life can be substantially longer than what has been previously estimated. One reason for a longer apparent half-life of the decline in serum $25(\mathrm{OH}) \mathrm{D}$, compared to a tracer $25(\mathrm{OH}) \mathrm{D}$ compound, is because firstly, unmetabolised vitamin $\mathrm{D}$ is released from tissue stores built up during vitamin $D$ supplementation, and secondly, there is a background of newly acquired vitamin $\mathrm{D}$ from the environment or diet that continues to be generate $25(\mathrm{OH}) \mathrm{D}$.

At one year after the end of the clinical trial, the group as a whole met the $50 \mathrm{nmol} / \mathrm{L}$ criterion for serum 25 $(\mathrm{OH}) \mathrm{D}$ as recently established by US Institute of Medicine. While this was apparently reassuring, the further decline in $25(\mathrm{OH}) \mathrm{D}$ shown here emphasizes the need for sustained awareness and monitoring of vitamin D status in nursing home residents. Follow-up reports after discontinuation of vitamin D and calcium supplementation are sparse. One report of a similar population that was provided lower doses of vitamin $\mathrm{D}$, showed that bone turnover markers had returned to baseline by two years

Table 2 Biochemical values and BMD changes before vitamin D bread consumption, at baseline of follow-up study (after 12 mo of vitamin D bread consumption) and after 12 and 36 months the supplementation with vitamin D was discontinued

\begin{tabular}{|c|c|c|c|c|c|c|c|}
\hline Parameter & $\begin{array}{l}\text { Vitamin D bread } \\
\text { consumption }(-12 \mathrm{mo})\end{array}$ & $\begin{array}{l}\text { Baseline of follow-up } \\
\text { study (0 month) }\end{array}$ & $\begin{array}{l}12 \text { month } \\
\text { follow-up }\end{array}$ & $\begin{array}{l}\text { 36-month } \\
\text { follow-up }\end{array}$ & P-value $^{1}$ & P-value ${ }^{2}$ & P-value ${ }^{3}$ \\
\hline $\begin{array}{l}\text { Serum calcium } \\
\text { (Normal: } 2.15-2.55 \mathrm{mmol} / \mathrm{L} \text { ) }\end{array}$ & $2.30 \pm 0.14$ & $2.31 \pm 0.13$ & $2.26 \pm 0.13$ & $2.29 \pm 0.15$ & 0.18 & 0.49 & 0.07 \\
\hline $\begin{array}{l}\text { Serum 25(OH)D } \\
\text { (Sufficiency: 50-125 nmol/l) }\end{array}$ & $29.8 \pm 9.3$ & $127.3 \pm 37.8$ & $64.9 \pm 24.8$ & $28.0 \pm 15.0$ & $<0.001$ & $<0.001$ & $<0.001$ \\
\hline $\begin{array}{l}\text { Serum PTH } \\
\text { (Normal: } 16-62 \text { pg/ml) }\end{array}$ & $60.2 \pm 42.6$ & $18.8 \pm 15.6$ & $46.7 \pm 21.2$ & $48.4 \pm 18.4$ & $<0.001$ & $<0.001$ & $<0.001$ \\
\hline Lumbar spine BMD (g/cm2) & $0.825 \pm 0.113$ & $0.858 \pm 0.134$ & $0.855 \pm 0.146$ & $0.867 \pm 0.142$ & 0.81 & 0.32 & 0.65 \\
\hline Total hip BMD (g/cm2) & $0.736 \pm 0.128$ & $0.927 \pm 0.130$ & $0.913 \pm 0.130$ & $0.907 \pm 0.121$ & 0.02 & 0.02 & 0.14 \\
\hline
\end{tabular}

$\mathrm{N}=23$, Data expressed in mean $\pm \mathrm{SD}$

${ }^{1}$ Student's $t$ test for paired data (baseline vs. 12 month follow-up).

${ }^{2}$ Student's t test for paired data (baseline vs. 36 month follow-up).

${ }^{3}$ Repeated-measures ANOVA. The interaction effect between sex and age was not statistically significant for any variable. There was a statistically significant main effect for age on $25(\mathrm{OH}) \mathrm{D}(\mathrm{F}=4.69, \mathrm{p}=0.007$, partial eta squared $=0.92)$ and for gender on total hip $\mathrm{BMD}(\mathrm{F}=7.08, \mathrm{p}=0.05, \mathrm{partial}$ eta squared $=0.59)$. 
after discontinuation, but serum 25(OH)D concentrations were not reported [8].

The present report is to our knowledge the longest follow-up after discontinuation of vitamin $\mathrm{D}$, and it does show a sustained biochemical benefit to the one-year point, in that the serum $25(\mathrm{OH}) \mathrm{D}$ exceeded $50 \mathrm{nmol} / \mathrm{L}$. However, by follow-up Year 3, the benefits of vitamin D fortification, were essentially gone. At follow-up Year 1, PTH had increased significantly from the end-of-vitamin D baseline. At follow-up Year 3, there was evidence that bone loss had progressed at the hip, but since there was no reference group in this study, the bone loss may reflect the normal age-related decline. The strength of this study is in its 3-yr characterization of the progression of the decline in $25(\mathrm{OH}) \mathrm{D}$ in older adults who had beforehand, received enough vitamin $D$ to achieve $25(\mathrm{OH}) \mathrm{D}$ concentrations that most would consider to be in the optimal range. Among the weaknesses of this work is the lack of a reference group against which to compare the variables studied.

\section{Conclusions}

In retrospect, it is unfortunate that the serum 25(OH)D concentrations eventually returned to the osteomalacic levels present before the subjects initially entered the breadfortification clinical trial. Lessons learned here are, firstly, that vitamin $\mathrm{D}$ nutritional status exhibits a long half-life in the body, whereby follow-up testing even at 1 year after a change in dose may not reflect a true plateau (i.e. steadystate) value; and secondly, that when a need for nutrient is established, even if this recognition is as part of a research protocol, then the appropriate action is to institute corrective measures beyond the extent of the research protocol.

\section{Competing interests}

The authors declare that they have no conflict of interests.

\section{Authors' contributions}

The authors' responsibilities were as follows: VM principal investigator, study concept and design, acquisition of data, analysis and interpretation of the data, drafting of the manuscript; RV study concept and design, analysis and interpretation of the data; critical revision of the manuscript. Both authors read and approved the final manuscript.

\section{Acknowledgements}

The authors wish to thank to Professor Corina Galesanu for her valuable review of the results and suggestions, and to technician Valentin Zaharia for performing the DXA scans.

\section{Author details}

'Department of Pathophysiology, Grigore T. Popa University of Medicine and Pharmacy, 16 Universitatii str, lasi 700115, Romania. ${ }^{2}$ Department of Laboratory Medicine and Pathobiology, University of Toronto, Toronto, VM, Canada. ${ }^{3}$ Department of Nutritional Sciences, University of Toronto, Toronto, RV, Canada.

\section{References}

1. Harris SS, Soteriades E, Coolidge JA, Mudgal S, Dawson-Hughes B: Vitamin D insufficiency and hyperparathyroidism in a low income, multiracial, elderly population. J Clin Endocrinol Metab 2000, 85(11):4125-4130.

2. Meyer HE, Smedshaug GB, Kvaavik E, Falch JA, Tverdal A, Pedersen JI: Can vitamin $D$ supplementation reduce the risk of fracture in the elderly? A randomized controlled trial. J Bone Miner Res 2002, 17(4):709-715.

3. Mocanu V, Stitt PA, Costan AR, Voroniuc O, Zbranca E, Luca V, Vieth R: Long-term effects of giving nursing home residents bread fortified with 125 microg (5000 IU) vitamin D(3) per daily serving. Am J Clin Nutr 2009, 89(4):1132-1137.

4. US Institute of Medicine: Dietary Reference Intakes for Calcium and Vittamin D. Washington, DC: National Academy Press; 2011.

5. Holick MF: Optimal vitamin D status for the prevention and treatment of osteoporosis. Drugs Aging 2007, 24(12):1017-1029.

6. Olkowski AA, Aranda-Osorio G, McKinnon J: Rapid HPLC method for measurement of vitamin D3 and 25(OH)D3 in blood plasma. Int J Vitam Nutr Res 2003, 73(1):15-18.

7. Vieth R: The Pharmacology of Vitamin D. In Vitamin D. Third Editionth edition. Edited by Feldman D, Pike JW, Adams JS. New York: Academic; 2011:1041-1066.

8. Dawson-Hughes B, Harris SS, Krall EA, Dallal GE: Effect of withdrawal of calcium and vitamin $D$ supplements on bone mass in elderly men and women. Am J Clin Nutr 2000, 72(3):745-750.

doi:10.1186/1475-2891-12-137

Cite this article as: Mocanu and Vieth: Three-year follow-up of serum 25hydroxyvitamin $D$, parathyroid hormone, and bone mineral density in nursing home residents who had received 12 months of daily bread fortification with $125 \mu \mathrm{g}$ of vitamin $D_{3}$. Nutrition Journal 2013 12:137.

\section{Submit your next manuscript to BioMed Central and take full advantage of:}

- Convenient online submission

- Thorough peer review

- No space constraints or color figure charges

- Immediate publication on acceptance

- Inclusion in PubMed, CAS, Scopus and Google Scholar

- Research which is freely available for redistribution 